This item was submitted to Loughborough's Research Repository by the author.

Items in Figshare are protected by copyright, with all rights reserved, unless otherwise indicated.

\title{
Opportunities and challenges for location aware computing in the construction industry
}

PLEASE CITE THE PUBLISHED VERSION

PUBLISHER

(c) The Association for Computing Machinery

LICENCE

CC BY-NC-ND 4.0

REPOSITORY RECORD

May, Andrew, Val Mitchell, Sarah L. Bowden, and Tony Thorpe. 2019. "Opportunities and Challenges for Location Aware Computing in the Construction Industry”. figshare. https://hdl.handle.net/2134/2803. 
This item was submitted to Loughborough's Institutional Repository by the author and is made available under the following Creative Commons Licence conditions.

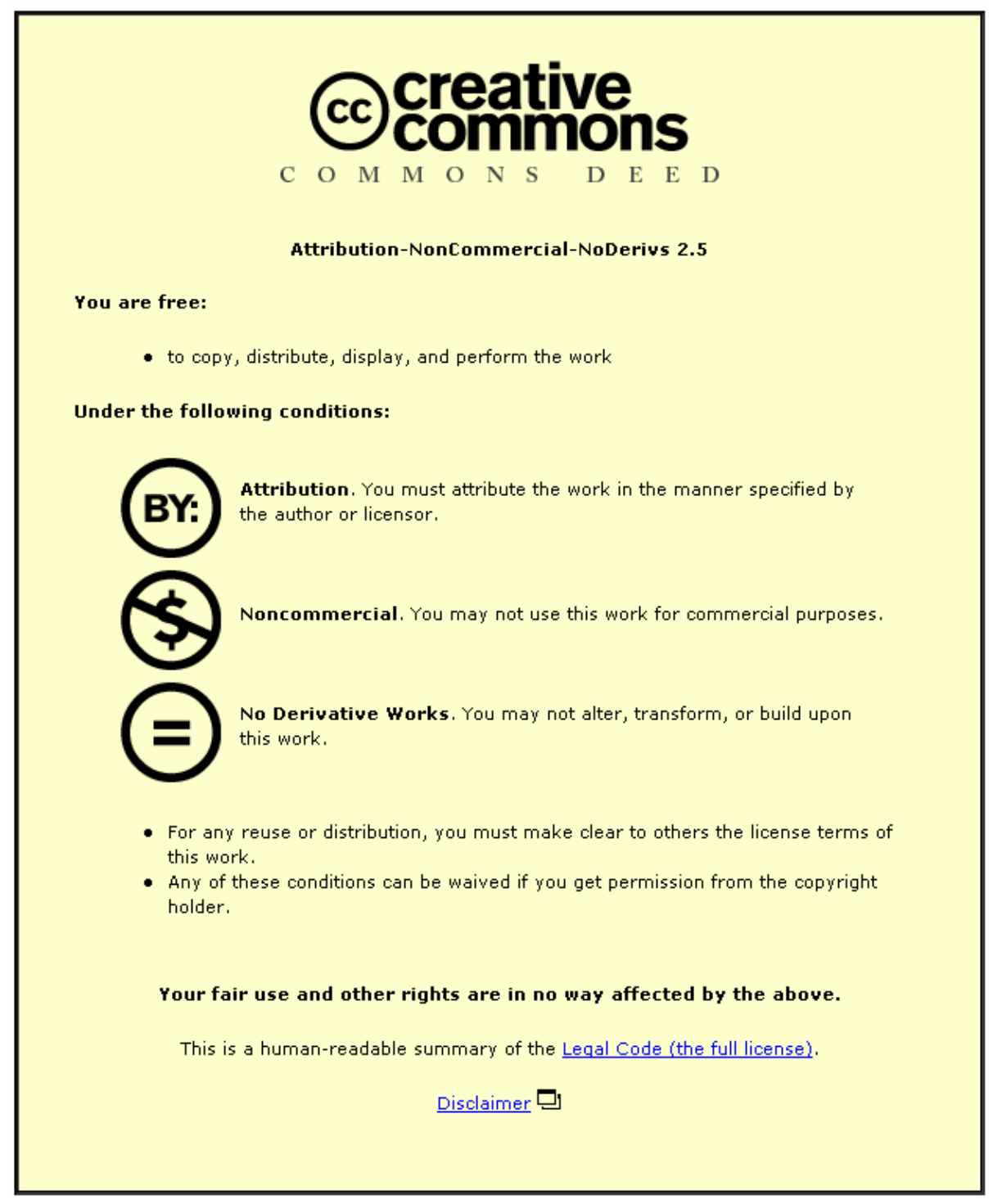

For the full text of this licence, please go to: http://creativecommons.org/licenses/by-nc-nd/2.5/ 


\section{Opportunities and Challenges for Location Aware Computing in the Construction Industry}

\author{
Andrew May \\ ESRI \\ Loughborough \\ University \\ Loughborough \\ LE11 3UZ, UK \\ +44 (0)1509 226906 \\ a.j.may@ lboro.ac.uk
}

\author{
Val Mitchell \\ ESRI \\ Loughborough \\ University \\ Loughborough \\ LE11 3UZ, UK \\ $+44(0) 1509226967$ \\ v.a.mitchell@lboro.ac.uk
}

\author{
Sarah Bowden \\ Arup \\ 13 Fitzroy Street \\ London \\ W1T 4BQ UK \\ +44 (0)207 7553177 \\ sarah.bowden@arup.com
}

\author{
Tony Thorpe \\ Loughborough \\ University \\ Loughborough \\ LE11 3TU, UK \\ $+44(0) 1509223771$ \\ a.thorpe@ @boro.ac.uk
}

\begin{abstract}
This paper describes the opportunities for location aware computing to enhance information capture and use within the construction industry. The construction industry is characterized as being slow to take up innovative mobile ICT, despite the highly mobile workforce who must collaborate with a range of on and off-site personnel, and make use of large volumes of information. Based on fieldwork and workshop activities within COMIT (a large-scale mobile IT project within the construction industry), the information used within two key business processes - health and safety audits, and site design problem resolution - is outlined, and the opportunities for support by location aware computing discussed. Some potential challenges are also identified, as is the need to understand how to provide real value (as opposed to just information) to the end user.
\end{abstract}

\section{Categories and Subject Descriptors}

H.1.2 [Models and Principles]: User/Machine Systems - human factors

\section{General Terms}

Design, Human Factors.

\section{Keywords}

construction industry, location aware computing, user-centered design, human factors

\section{INTRODUCTION}

Due to the nature of the construction industry, construction site workers are required to be highly mobile, communicate effectively with other personnel on and off site, and to analyse and synthesise large volumes of information within project critical time-frames [2]. These requirements present considerable opportunities for enhancing business processes using innovative mobile ICT.

Permission to make digital or hard copies of all or part of this work for personal or classroom use is granted without fee provided that copies are not made or distributed for profit or commercial advantage and that copies bear this notice and the full citation on the first page. To copy otherwise, or republish, to post on servers or to redistribute to lists, requires prior specific permission and/or a fee.

MobileHCI'05, September 19-22, 2005, Salzburg, Austria.

Copyright 2005 ACM 1-59593-089-2/05/0009...\$5.00.
However the nature of the construction industry also presents a range of challenges which must be overcome if successful solutions are to be developed. These include: the challenging physical environment within which the technology must operate successfully, the variable levels of education and training of some of the workforce, and the multiple stakeholders collaborating on and off site.

A key determinant of the success of mobile services (within the construction or any other industry) will be whether they add value to the end-user of the technology, independently of the theoretical benefits to the organisational business process. A problem identified long ago by [8] was that of the benefits of computer supported cooperative working not being realised by those who expend the effort actually using the technology. There are some basic questions from an end user's perspective: Do the perceived benefits of using a mobile device outweigh the perceived or actual effort involved in using it? Why should they use a mobile device to access information online when they can ask a colleague or phone their head office? Why should they use electronic data capture when a camera or notepad and pen will suffice for their purposes? Will they be motivated to use a mobile device out on site when they can wait until they get back to the site office? Mobile solutions clearly have to offer real value to the end user if they are to be successful in a real work context, and location aware computing can play a role in supporting this requirement.

The aim of this paper is to discuss the opportunities and challenges for location aware computing in the construction industry, based on workshop and fieldwork activities undertaken within the COMIT project (described in Section 3 below). By identifying key business processes, communication and information requirements, and location attributes associated with that information, it is possible to identify where location awareness can both enhance business processes and add real value to an end-user.

\section{MOBILE ICT IN CONSTRUCTION}

It is generally agreed that the uptake of innovative IT within the construction industry is disappointing, especially when related to the substantial research effort and expenditure taking place within this field [1]. Despite this, there are examples of mobile IT, and even location aware computing that have been implemented successfully within the industry, and [3] have highlighted how 
successful implementations of mobile ICT have gained user acceptance and demonstrated a typical return on investment within one year of adoption.

Over the last 20 years, mobile ICT has been applied to a wide range of processes within the construction industry. Recent examples include progress records [5], maintenance inspections [12] and monitoring of foundation pile sinking [13]. There have also been examples of location aware computing being used successfully within the construction industry. Vehicle tracking via GPS is used routinely in many fleet management operations, and the maintenance of situational awareness of construction equipment is described by [11]. In addition, a case study presented by [3] describes the use of a PDA with GPS tracker that was developed to undertake earthworks examinations. Other case studies described by [3] have used a variety of PDAs, tablet PCs, mobile phones, and digital pen and paper, with off the shelf, customized and bespoke software, and data transfer via mobile/static syncronisation, GSM/GPRS networks, and wireless LAN.

\section{THE COMIT PROJECT}

The COMIT project (Construction Opportunities for Mobile IT) is a two year research and development project funded by the DTI and led by Arup. A major component of this project was the formation of a project community comprising construction companies, technology providers, research and development institutions and dissemination companies. The main objectives of COMIT are to promote the development and uptake of mobile IT within the construction industry. Key activities within COMIT are the identification of critical business processes, documentation of the 'as-is' methods of working, user requirements analysis, and specification and development/implementation of IT demonstrators based on the 'to-be' business process scenarios. COMIT is seen as one of the major mobile IT initiatives within the construction industry, with a total community comprising approximately 40 partners.

Partway through the COMIT project, a workshop was undertaken to investigate the potential for location aware computing to support critical business processes within the industry. The COMIT community had previously assessed more than 10 separate business processes in order to focus on the requirements and specification of mobile IT to support four of these. The criteria used to select these four processes were based on the availability of potential solutions, the organizational and user benefits and the ease of implementation. These four selected processes were:

- Onsite health and safety audits

- Site design problem resolution

- Monitoring progress on site

- Mobile workforce maintenance inspections

Present at the workshop were approximately 30 stakeholders, with the construction industry being represented by IT managers, inhouse IT champions and end-user representatives with responsibility for particular business processes (eg health and safety managers). The workshop initially characterised mobile computing within the context of the construction industry, and then described a range of location aware capabilities as follows:
- 'Tell me how to get somewhere'

- 'Find my nearest person place or thing'

- 'Identify hazards associated with particular areas'

- 'Give me information relevant to where I am, where I am looking, or where I will be'

Subsequently, the workshop participants, grouped within their process teams, assessed the opportunities and challenges for location aware computing in connection to each business process. This was undertaken using boards and physical props. A key output was the identification of the information needed to undertake that process, the individuals who must communicate or share information within that process, and the information generated by that process. The information needed or generated was tagged as either having, or not having, a critical location attribute.

\section{RESULTS}

An overview of the workshop output relating to two of these processes, (1) health and safety audits, and (2) site design problem resolution, is shown in Figures 1 \& 2. These summarise the information needed to undertaken those processes, the personnel involved (who may belong to various organizations) and the information generated by each process. Information labeled thus** is that which was identified by stakeholders as having a critical location attribute.

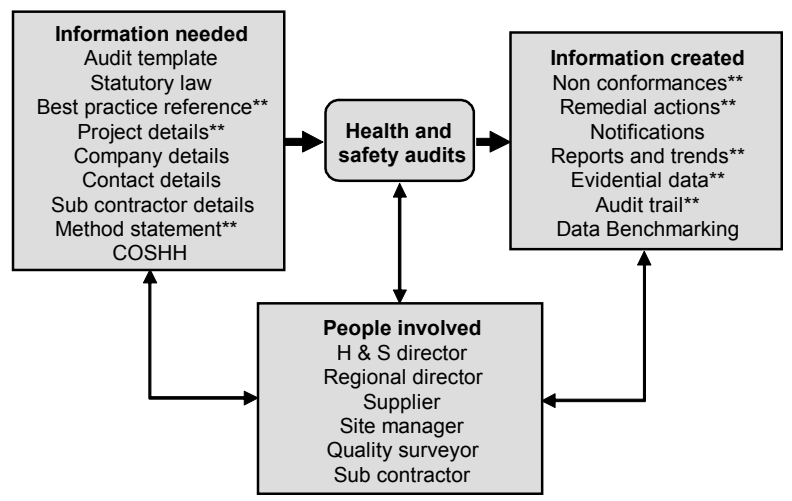

Figure 1. Overview of onsite health and safety audits. ** identifies critical location attributes.

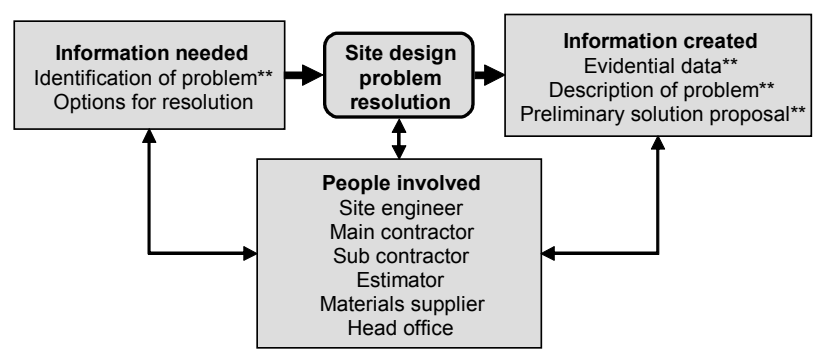

Figure 2. Overview of site design problem resolution. ** identifies critical location attributes. 
Space precludes a more detailed description of the existing or envisioned processes involved; in particular they are clearly not 'black boxes' as shown in Figures $1 \& 2$. The COMIT project has spent considerable effort in both understanding the existing business processes, and mapping the capabilities of mobile IT onto projections for future working scenarios. Apparent from Figure $1 \& 2$ is the extent to which location is a key attribute of much of the information involved in both health and safety inspections and on-site problem resolution. This does not imply that either mobile services in general, or location aware services will necessarily add value to the end user. With some of the operations investigated on site during the COMIT fieldwork (eg sinking of foundation piles), the spatial location of work crews changes relatively slowly and/or the work context is accurately spatially referenced. (Foundation piles are typically sunk within $+/-75 \mathrm{~mm}$ of a predetermined location). However, health and safety audits are a target process where location aware delivery of information can guide the inspection process, and where location based tagging of collected data can aid its analysis by the inspector, the development of a history or 'electronic paper trail', and the synthesis and re-use of this data within the wider context of the organisation.

A typical application relates to a health and safety issue that arose with members of the public crossing a construction site entrance in a busy town centre development. There had been a history of complaints by the public of trips or near trips at this particular location, with doubts over the veracity of some of these claims. The health and safety inspector needed to include inspection of this particular location as part of a regular safety audit of the entire site. She used recall of event histories and a judgement of current importance to influence the extent and nature of data capture at various locations on site. This resulted in a large number of digital photographs being taken where members of the public had made complaints. Back in the site office, these were then downloaded, labeled and emailed within the organization. There is clearly opportunity for both providing location-relevant information to the inspector at different locations, and also enabling the tagging of data with location attributes as it is collected.

Location aware services to support the health and safety inspection process should therefore:

1. Provide access to the history of incidents occurring at a particular location

2. Provide access to the current status of a problem, including the priority associated with an ongoing issue

3. Present data capture templates (used in the widest sense of the term) that are relevant to the context of the problem

4. Enable location and entity-based tagging of collected data.

The creation of location-tagged data then helps the formation of the audit record for that day, the degree to which nonconformances arise at particular locations, the desired or implemented solutions to specific problems, and the generation of an audit/resolution history which can be used by the organization.

The use of location awareness in the manner outlined above capitalises on two of the three functional modes as described by [6]: it enables (or makes available) the presentation of relevant information to the user; and it enables location-based tagging of information for later retrieval.

For location aware services to be successful in the construction industry, they must operate with location as defined by [6] where this also includes the orientation and elevation of the user, and potentially the spatial relationships between different physical entities on site. Additionally, a service should also be mindful of the comments by [10] where they highlight that rather than identifying location per se, it is often more useful to know what an individual is looking at.

Although a potential service could either use active or passive awareness [4] to deliver information to the inspector, a passive approach is likely to be more successful given the multitasking, and potentially dangerous nature of the inspector's role (see below).

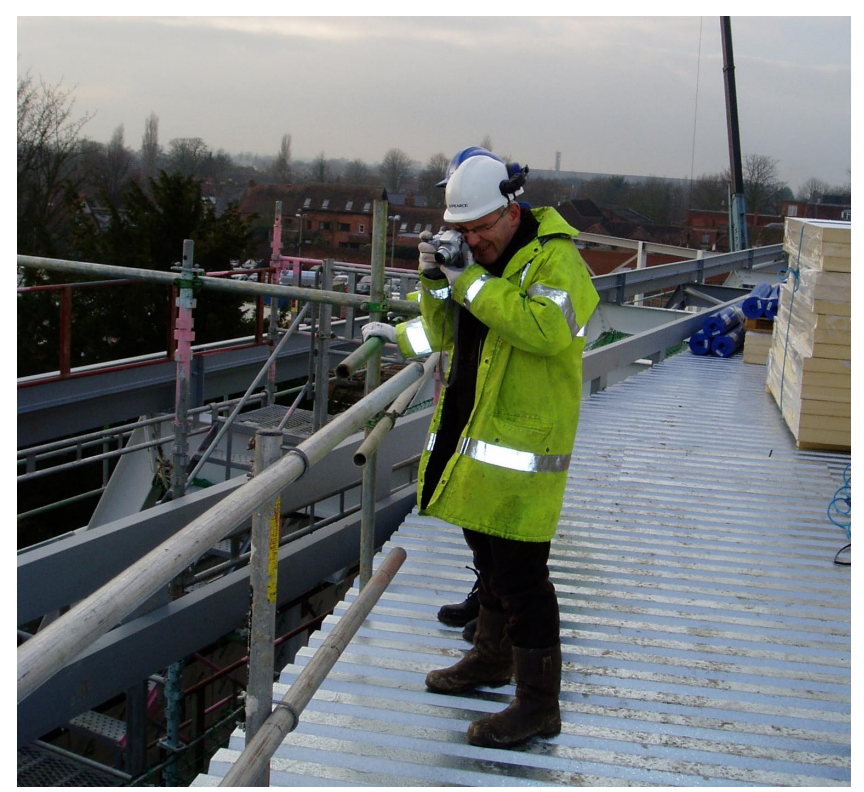

Figure 3. Health and safety audit

\section{CONCLUSIONS}

The COMIT project has identified a series of opportunities for mobile ICT to increase the competitiveness of the construction industry. By increasing the ease of interaction with information, location aware computing can potentially reduce the barriers to accessing, generating and re-using information out on a construction site.

Although the theoretical arguments for location aware computing within the construction industry are quite compelling, there are a number of challenges that must be overcome. Technical challenges include overcoming problems with limited battery life, reducing the interference with communication links caused by site objects, and determining accurate location and orientation information. In terms of adding value to end users, mobile devices, including those which are location aware, must avoid the tendency to merely replicate paper forms with electronic forms. Instead service design must be based around the information content that makes a real difference to the use, and delivery via what is in effect a 'letterbox' view of a wider information world. 
Flach [7] puts this eloquently. He quotes Holnagel [9] who states the need for interfaces to 'provide the right information, at the right time and in the right way' (p.221). Flach identifies that this is not the answer to interface design; rather the fundamental question is to define 'right'.

\section{FUTURE WORK}

At the time of writing (May 2005), the evaluation of the demonstrators within the construction industry is still taking place. This work, plus investigation of what 'right' is in the above context, will continue throughout 2005 and will be reported more fully at a later date.

\section{ACKNOWLEDGMENTS}

The authors would like to acknowledge the contributions made by the COMIT community. Further details of COMIT, and the partners involved, can be found at www.comitproject.org.uk.

\section{REFERENCES}

[1] Anumba, C. J. (1998). Industry uptake of construction IT innovations - key elements of a proactive strategy, in The life-cycle of construction IT innovations - Technology transfer from research to practice. B. C. Bjoerk \& A. Jagbeck, eds., Stockholm, 77-83.

[2] Bowden, S., Dorr, A., Thorpe, A., \& Anumba, C. J. 2004. Mapping site processes for the introduction of mobile IT, in ECPPM 2004 eWork and eBusiness in Architecture, Engineering and Construction. A. Dikbas \& R. Scherer, eds., The Netherlands, A.A. Balkema Publishers, 491-498.

[3] Bowden, S., Dorr, A., Thorpe, A., Anumba, C. J., \& Gooding, P. 2005. Making the Case for Mobile IT in Construction, in International Conference on Computing in Civil Engineering. Awaiting publication

[4] Chen, G., \& Kotz, D. (2000). A Survey of Context-Aware Mobile Computing Research: Dartmouth Computer Science Technical Report TR2000-381.

[5] Cox, S., Perdomo, J., \& Thabet, W. 2002. Construction Field Data Inspection Using Pocket PC Technology, in International Council for Research and Innovation in
Building and Construction, CIB w78 conference 2002, Distributing

[6] Dey, A. K., Abowd, G. D., \& Salber, D. (2001). A conceptual framework and a toolkit for supporting the rapid prototyping of context-aware applications. Human-Computer Interaction, 16(2-4), 97-166.

[7] Flach, J. M., Vicente, K. J., Tanabe, F., Monta, K., \& Rasmussen, J. (1998, October 5-9, 1998.). An Ecological Approach to Interface Design. Paper presented at the Human-System Interaction: The Sky's No Limit. Proceedings of the Human Factors and Ergonomics Society 42nd Annual Meeting, Chicago, Illinois, Santa Monica, California.

[8] Grudin, J. 1988. Why CSCW applications fail: Problems in the design and evaluation of organizational interfaces. In Proceedings of CSCW 88 (pp 85-93). Portland, OR, USA.

[9] Hollnagel, E. (1988). Information and reasoning in intelligent decision support systems. In E. Hollnagel, G. Mancini \& D. D. Woods (Eds.), Cognitive engineering in complex dynamic worlds. London: Academic Press.

[10] Long, S., Aust, D., Abowd, G., \& Atkeson, C. (1996). Cyberguide: Prototyping Context-Aware Mobile Applications. Short paper in the Proceedings of 1996 Conference on Human Factors in Computing Systems (CHI '96, April 13-18). Vancouver, CA. Also available at: www.cc.gatech.edu/fce/cyberguide/pubs/chi96cyberguide.html.

[11] Oloufa, A. Ikeda, M. and Oda, H. 2003. Situational awareness of construction equipment using GPS, wireless and web technologies. Automation in Construction 12, 737748.

[12] Rojas, E. M. \& Songer, A. D. 1997. FIRS: A vision of the future of building inspection, in Proceedings of the Forth Congress in Computing in Civil Engineering. ASCE, 25-32.

[13] Ward, M., Thorpe, A., Price, A., \& Wren, C. 2003. SHERPA: Mobile wireless data capture for piling works. Journal of Computer Aided Civil and Infrastructure Engineering 18(4): 200-220. 